\title{
PRIMARY HYDATID CYST OF THE LEFT KIDNEY WITH HYDATIDURIA: A RARE CASE
}

Pankaj Saunakiya ${ }^{1}$, Manish Jain², Ashok Kumar ${ }^{3}$

\section{HOW TO CITE THIS ARTICLE:}

Pankaj Saunakiya, Manish Jain, Ashok Kumar. "Primary Hydatid Cyst of the Left Kidney with Hydatiduria: A Rare Case". Journal of Evolution of Medical and Dental Sciences 2014; Vol. 3, Issue 36, August 18; Page: 94459448, DOI: $10.14260 /$ jemds/2014/3218

ABSTRACT: Hydatid cyst involving the urinary tract is relatively uncommon, we report a case of isolated hydatid cyst of the left kidney in a 55year old female presented with the left flank pain and passage of whitish grape like structures in urine (Hydatidurea).Clinical features mimic renal tumour, Diagnosis made by ultrasound and Contrast Enhanced Computed Tomograpgy (CECT) of the abdomen, patient underwent left nephrectomy after giving a course of Albendazole. Post -operative period was uneventful and patient is in good health.

KEYWORDS: Primary Renal Hydatid cyst, Hydatiduria, Nephrectomy.

INTRODUCTION: Hydatid disease affects both human and animals such as sheep, dog and horses. It is caused in humans by larval stage of Echinococcus granulosus, E. multilocularis and E. vogali.

Hydatid cyst involving the urinary tract is relatively uncommon, In humans hydatid disease involves the liver in $75 \%$ of cases and the lung in $15 \%$ of cases, secondary involvement due to hematogenous dissemination may be seen in almost any anatomical location, renal involvement is extremely rare $(2-4 \%)$ even in endemic areas.[1] Patient with primary involvement of kidney remains asymptomatic for many years until the rupture of cyst into collecting system which leads to acute renal pain and hydatidurea.

CASE REPORT: A 55 year old female presented with the dull aching pain in left lumbar region for one year and occasional passage of whitish grape like structures in urine for one month, there was no history of hematuria or fever. Abdominal examination demonstrated tenderness in left lumbar region and palpable left kidney, rest of the abdomen is normal.

On evaluation her routine investigations were within normal limits except the presence of yeast like cells in urine, chest and abdominal x-ray were normal. Ultrasound of abdomen showed left minimal hydroureteronephrosis and a well-defined septated multicystic lesion measuring about $63.20 \times 52.10 \times 53.00 \mathrm{~mm}$ (Fig. 1a) with few calcifications in the wall involving lower pole of the left kidney, Intravenous Urogram (IVU) shows bilateral normal functioning kidney.

CECT abdomen revealed rounded hypoechoic cystic lesion(measuring approx 65.00x71.00 $\mathrm{mm}$ ) with multiple internal septation arising from left kidney with speck of calcification in the wall of the lesion (Fig. 1b, 1c), the lesion is causing mass effect over pelvicalyceal system no other cystic lesion found in the liver, lungs or right kidney.

The patient underwent surgery and the mass lesion is found in lower pole of the left kidney (Fig. 2a) which is adhered to the transverse mesocolon and descending colon, nephrectomy was done without cyst perforation or any spilling of cyst contents in the peritoneal or retroperitoneal cavity, the specimen is removed en-bloc (Fig.2b). During surgery the liver was normal in appearance and no other hydatid cyst were seen in the abdomen. 
The resected specimen showed a large white thick walled cyst containing clear fluid with numerous daughter cysts of varying size (Fig.2c).The gross findings confirmed the diagnosis of hydatid cyst of the kidney which is latter confirmed by histopathological examination. The patient received two weeks of Albendazole preoperatively and same was continued for two weeks in the post-operative period, the post-operative period was uneventful.

DISCUSSION: Renal hydatid cysts are usually Multiloculated consist of single large cyst and smaller daughter cysts of varying sizes, multiple hydatid cysts in kidney were also reported. Renal pelvicalyceal system is dilated in most of the cases and microscopic hydatiduria is seen in $10-20 \%$ of renal hydatidosis. [2]

Imaging studies are suggestive, but usually inconclusive, especially in a complicated cyst that mimics renal tumor or ureteropelvic junction obstruction appearance. [3]

There is no specific laboratory finding for renal hydatid disease. In $20 \%$ to $50 \%$ of cases, moderate eosinophilia is present. The Casoni and Weinberg tests have been abolished due to their little efficacy, ${ }^{[4]}$ a highly specific test $(79 \%)$ for hydatid disease is immunoelectrophoresis against arch-5.

The specific diagnosis of hydatid disease can be made by identifying protoscolices or hooklets in cyst fluid but usually fluid aspiration is not recommended due to risk of fluid leakage and anaphylaxis reaction. Calcification of the cyst is not restricted to the inactive cyst types, but occurs in all stages and in up to $50 \%$ of cysts. [5]

Surgery is the treatment of choice in renal hydatid cyst, Kidney-sparing surgery (cystectomy with pericystectomy) is possible in most cases (75\%).Nephrectomy (25\% of cases) must be reserved for destroyed kidneys. ${ }^{[6]}$ There are few reports of laparoscopic removal of renal hydatid but chances of cyst rupture, dissemination and incomplete removal of the hydatid cyst are quite high.[7]

Albendazole is medical treatment of choice in disseminated hydatid disease, localized disease with poor surgical risk, ruptured cysts and significant intraoperative spillage. Pre and postoperatively use of albendazole decreases the cyst wall tension thus reducing the risk of spillage during surgery and prevent the chance of anaphylaxis.[8] Finally for a non-functioning grossly enlarged kidney hydatid cyst should be in the differential diagnosis.

\section{REFERENCES:}

1. Afsar H, Yagci F, Aybasti N, Meto S. Hydatid disease of the kidney. Br J Urol 1994; 73: 17-22.

2. S. Zmerli, M Ayed, A Horchani, I Chami, M El Ouakdi, M R Ben Slama. Hydatid cyst of the kidney: diagnosis and treatment. World Journal of Surgery, vol. 25, no. 1, pp. 68-74, 2001.

3. Angulo JC, Sanchez-Chapado M, Diego A, Escribano J, Tamayo JC, Martin L. Renal echinococcosis: clinical study of 34 cases. J Urol. 1997; 157: 787-94.

4. Sountoulides P, Zachos I, Efremidis S, Pantazakos A, Podimatas T. Nephrectomy for benign disease? A case of isolated renal echinococcosis. Int J Urol. 2006; 13: 174-6.

5. Hosch W, Stojkovic M, Janisch T, Kauffmann GW, Junghanss T. The role of calcification for staging cystic echinococcosis (CE). Eur Radiol 2007; 17(10): 2538-45.

6. Mongha R, Narayan S, Kundu A K. Primary hydatid cyst of kidney and ureter with gross hydatiduria: A case report and evaluation of radiological features. Indian J Urol 2008 Jan-Mar; 24 (1): 116-117. 


\section{CASE REPORT}

7. Basiri, M. Nadjafi-Semnani, A Nooralizadeh. Laparoscopic partial nephrectomy for isolated renal hydatid disease. Journal of Endourology, vol. 20, no. 1, pp. 24-26, 2006.

8. Cushieri R J C Steele, A R Moosa. Treatment of Hydatid Cyst, Essential Surgical Practice, Arnold, 4th edition.

Fig. 1(a): Ultrasound showing multiloculated cystic lesion with well-defined wall with calcifications, (b) Axial and (c) Coronal Reconstructed CECT showing well defined cystic lesion involving the lower pole of the left kidney with wall calcifications (Arrows).

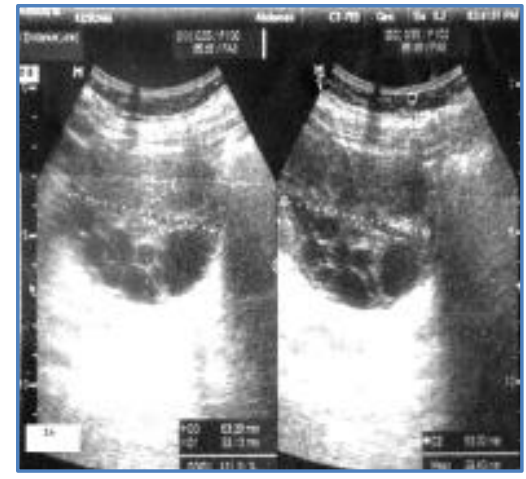

Fig. 1a

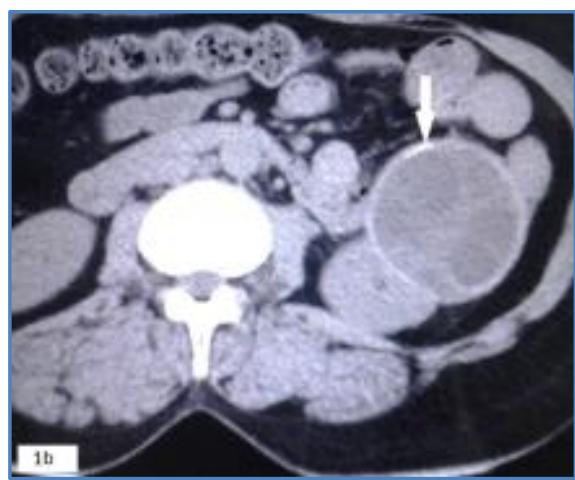

Fig. $1 b$

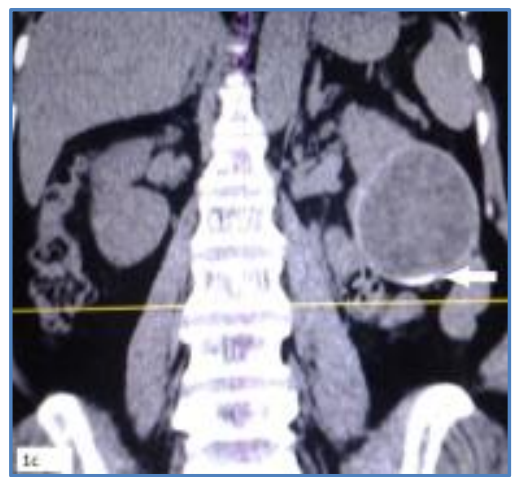

Fig. 1c

Fig. 2(a): Intraoperative view showing left kidney with cystic lesion at lower pole (b) Enbloc removed left kidney showing white coloured lesion in lower pole, (c) cut opened specimen showing large cyst (white arrow) with multiple daughter cysts (black arrow).

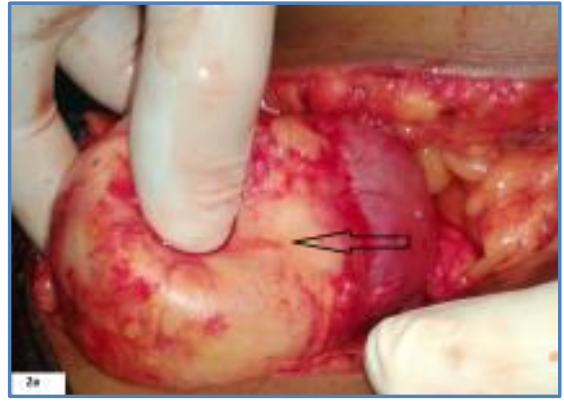

Fig. 2a

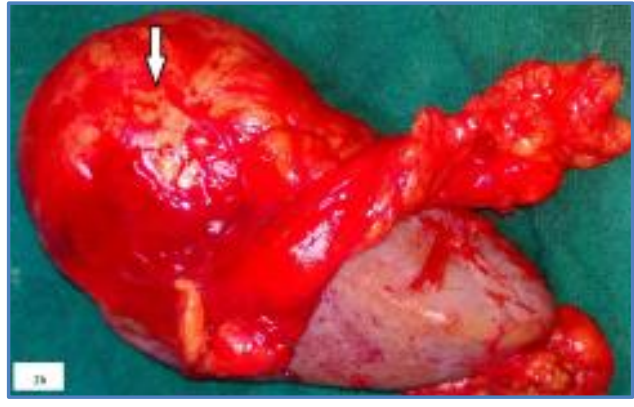

Fig. 2b

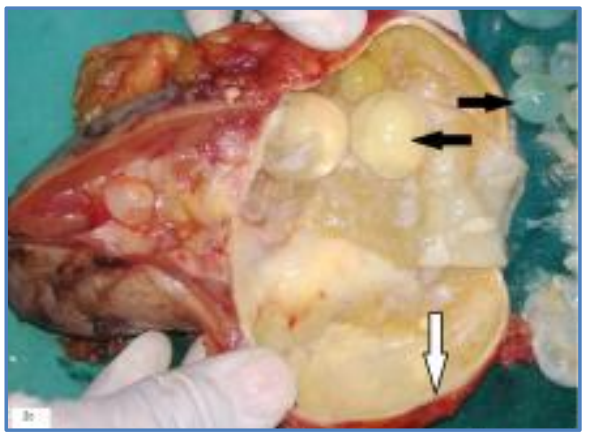

Fig. 2c 


\section{CASE REPORT}

\section{AUTHORS:}

1. Pankaj Saunakiya

2. Manish Jain

3. Ashok Kumar

\section{PARTICULARS OF CONTRIBUTORS:}

1. Assistant Professor, Department of Surgery, MLB Medical College, Jhansi, U. P.

2. Associate Professor, Department of Surgery, MLB Medical College, Jhansi, U. P.

3. Senior Resident, Department of Surgery, MLB Medical College, Jhansi, U. P.

\section{NAME ADDRESS EMAIL ID OF THE} CORRESPONDING AUTHOR:

Dr. Ashok Kumar,

B-103 Awas Vikas Colony,

Sitapur-261001, U.P.

Email: drashok79@gmail.com

Date of Submission: 01/08/2014.

Date of Peer Review: 02/08/2014.

Date of Acceptance: 09/08/2014.

Date of Publishing: 16/08/2014. 